\title{
Determination of Adiabatic Ionization Potentials and Electron Affinities of Energetic Molecules with the Gaussian-4 Method
}

\author{
M. Riad Manaa* \\ Lawrence Livermore National Laboratory \\ Energetic Materials Center \\ 7000 East Avenue \\ Livermore, CA, 94551
}

*Email: manaa1@1lnl.gov

(C) 2017. This manuscript version is made available under the Elsevier user license http://www.elsevier.com/open-access/userlicense/1.0/ 


\begin{abstract}
Adiabatic ionization potentials $\left(\mathrm{IP}_{a d}\right)$ and electron affinities $\left(\mathrm{EA}_{a d}\right)$ are determined with the Gaussian-4 (G4) method for the energetic molecules PETN, RDX, $\beta$ $\delta$-HMX, CL-17, TNB, TNT, CL-14, DADNE, TNA, and TATB. The $\mathrm{IP}_{a d}$ and EA $a d$ values are in the range of 8.43-11.73 and 0.74-2.86 eV, respectively. Variations are due to substitutional effects of electron withdrawing and donating functional groups.

Enthalpies of formation are also determined for several of these molecules to augment the list of recently reported G4 values. The calculated $\mathrm{IP}_{a d}$ and $\mathrm{EA}_{a d}$ provide quantitative assessment of such molecular properties as chemical hardness, molecular electronegativity, and "intrinsic" molecular physical hardness.
\end{abstract}


The exposure of energetic materials such as explosives and propellants to electromagnetic radiation represents an unwelcome stimulus that could lead to undesirable, if not catastrophic, events. When gamma radiation of various penetrating energies is impinged upon energetic solids, three possible outcomes are expected: photoelectron effect, Compton scattering, or pair production, which may induce chemical and/or mechanical changes in the pristine material. [1] Be it ultraviolet light or gamma rays, induced chemical and mechanical changes in these solids lead to degradation of their structural, physical, and chemical integrities. Irradiated thin layers of the explosive HMX with $\gamma$ rays in evacuated tubes at liquid nitrogen temperature showed significant enhanced sensitivity to impact, with frequent spontaneous explosions occurring at higher radiation doses. [2] Chemical changes in the insensitive explosive TATB due to both UV light and gamma irradiation showed a significant decrease in the onset of reaction exotherm. [3-5] While electron ejection from the irradiated material is one of the possible outcomes, that many of the organic energetic molecules do contain electron acceptor functional groups such as $-\mathrm{NO}_{2}$ may also result in electron capturing by the same material. For the purpose of rapid explosive detection, [6] studies using mass spectroscopic methods that included laser photon ionization [7] and dissociative negative ions spectroscopy [8-10] have been conducted to identify and probe unique fragments. Computational studies of activation barriers to dissociation of both negative and positively charged explosive molecules have also been reported. [11-13] The accurate determination of ionization potentials (IPs) and electron affinities (EAs) is thus important in quantifying the susceptibility of energetic materials to radiation effects. Interesting observations or concepts correlating explosive shock and impact sensitivities with 
chemical hardness or electronic band gaps can then be assessed based on such determinations. [14, 15]

Although many of the energetic solids and liquids have low vapor pressure, they are still amenable to molecular beam experiments. $[16,17]$ The dearth of experimental determinations of IPs and EAs of these materials, however, entice the effort to perform computational studies using the most accurate of quantum chemical methods. To facilitate comparison with any future experimental results, the adiabatic values of IPs and EAs must be determined. [18] From a theoretical perspective that assumes the BornOppenheimer approximation, the adiabatic valence ionization potential $\left(\mathrm{IP}_{a d}\right)$ and electron affinity $\left(\mathrm{EA}_{a d}\right)$ for a molecular species are defined as:

$$
\begin{aligned}
\mathrm{IP}_{a d}= & {\left[E_{\mathrm{e}}(\text { optimized cation })+\mathrm{ZPE}(\text { cation })\right]-} \\
& {\left[E_{\mathrm{e}}(\text { optimized neutral })+\mathrm{ZPE}(\text { neutral })\right] } \\
\mathrm{EA}_{a d}= & {\left[E_{\mathrm{e}}(\text { optimized neutral })+\mathrm{ZPE}(\text { neutral })\right]-} \\
& {\left[E_{\mathrm{e}}(\text { optimized anion })+\mathrm{ZPE}(\text { anion })\right] }
\end{aligned}
$$

where $E_{\mathrm{e}}$ is the electronic energy, and ZPE is the molecular zero-point vibrational energy. Thus, the calculations of $\mathrm{IP}_{a d}$ and $\mathrm{EA}_{a d}$ require the optimization of the neutral, cation, anion structures, and the associated frequency calculations of these structures. Due to their computational complexity, the use of highly-accurate electronic structure methods such as coupled cluster with single, double, and perturbative triple $(\operatorname{CCSD}(T))$ has been restricted to calculating vertical IPs and EAs values of relatively small to moderate size molecules. [19, 20] To obtain such values, only the neutral species is optimized followed by a one-point energy calculation at the same resulting equilibrium geometry for the ion of interest. Although computationally intensive for large-size molecules, composite quantum mechanical approaches are providing an alternative to the calculation of such 
properties as heat of formation, IPs and EAs with a purported achievement of the "chemical" accuracy limit. [21-24]

In this work, the $\mathrm{IP}_{a d}$ and $\mathrm{EA}_{a d}$ for the set of ten energetic molecules listed in Figure 1 are calculated using the Gaussian-4 (G4) composite method as implemented in Gaussian 09 program. $[22,25]$ In addition to containing some of the most commonly known explosive molecules of interest, such as PETN, HMX, RDX, TATB, and TNT, the list contains a variety of energetic structures with various effects. These include aromatic rings (as in TATB, TNT, TNB, and TNA), electron donor and acceptor functional groups (- $\mathrm{NH}_{2}$ and $-\mathrm{NO}_{2}$, respectively), $\mathrm{N}$-substituted rings (as in $\mathrm{HMX}$, and $\mathrm{RDX}$ ), furoxan rings (CL-14 and CL-17), and absence of ring structures altogether (PETN and DADNE). The sequence of ab initio calculations performed within the G4 method to obtain the total energy of a given molecular species at the MP4 and $\operatorname{CCSD}(\mathrm{T})$ level, in particular, represented a significant computational challenge that dedicated runs on a specialty computer platform with 500 GB of physical memory distributed among 32 CPUs had to be performed for over a period of 25 days for the 29 atoms PETN anion specie alone. Finally, enthalpies at $\mathrm{T}=298.15 \mathrm{~K}\left(\mathrm{H}_{298}\right)$ are also reported, which allow for the determination of enthalpies of formations $\Delta H_{f}^{0}(0 \mathrm{~K})$ and $\Delta H_{f}^{0}(298 \mathrm{~K})$ at 0 and $298.15 \mathrm{~K}$ for several species, thus expanding the list of recently reported $\Delta H_{f}^{0}$ values of energetic molecules. [26]

Table I reports the results of the calculated zero-point-corrected total electronic energies, $E_{0}=E_{e}+\mathrm{ZPE}$, the corresponding zero-point vibrational energies (ZPE), the enthalpies at $\mathrm{T}=298.15 \mathrm{~K}\left(\mathrm{H}_{298}\right)$ of the neutrals, cations, and anions species, and the resulting $\mathrm{IP}_{a d}$ and $\mathrm{EA}_{a d}$ as defined in equation (1). All species yielded equilibrium 
structures with positive vibrational frequencies of all the modes at the B3LYP/6-31G $(2 d f, p)$ level performed within the G4 method. As shown in Table I, all neutral species have larger ZPE s than their cations or anions, the largest being $4.2 \mathrm{kcal} / \mathrm{mol}$ difference between the neutral and anion of HMX in its $\delta$ conformation (discussed below), and 4.1 $\mathrm{kcal} / \mathrm{mol}$ difference between the same species in PETN. All cations yielded a relatively larger ZPEs than their corresponding anions with the exception of TNT.

$\mathrm{IP}_{a d}$ values range from 8.43 to $11.73 \mathrm{eV}$, and $\mathrm{EA}_{a d}$ from 0.74 to $2.86 \mathrm{eV}$. The $\mathrm{IP}_{a d}$ values are similar to other organic molecules, typically $\sim 8-11 \mathrm{eV}$. [20] Variations in the $\mathrm{IP}_{a d}$ values are due to interplay between the presence of the strong electron withdrawing $\mathrm{NO}_{2}$ group in all of the structures, which destabilizes the cations and leads to larger $\mathrm{IP}_{a d}$ values, and the presence of strongly $\left(-\mathrm{NH}_{2},-\mathrm{NR}_{2}\right)$ and weakly (alkyl: $-\mathrm{CH}_{3}$, phenyl: $\mathrm{C}_{6} \mathrm{H}_{5}$ ) electron donating groups. Both CL-17 and CL-14 contain similar ring structures and the datively-bonded, $\mathrm{N}$-oxide group $\left(-\mathrm{N} \rightarrow \mathrm{O}^{-}\right)$. The $\mathrm{IP}_{a d}$ of $\mathrm{CL}-17$ at $9.19 \mathrm{eV}$ is higher than CL-14's $(8.43 \mathrm{eV})$, due to the presence of one more electron withdrawing $-\mathrm{NO}_{2}$ replacing the electron donating $-\mathrm{NH}_{2}$, the only difference between the two molecules. Balancing effects between strongly donating and strongly withdrawing groups is also manifested for the lowest $\mathrm{IP}_{a d}$ values among all the molecules, that of CL-14, TATB $(8.56 \mathrm{eV})$, and DADNE $(8.92 \mathrm{eV})$. The three (two) $-\mathrm{NO}_{2}$ withdrawing groups are counterbalanced by the three (two) $-\mathrm{NH}_{2}$ donating groups in TATB (DADNE), leading to similarly "low" IP $a d$ values. The lower IP $a d$ for TATB than that of DADNE's could perhaps be explained due to the presence of the weakly electron donating phenyl group ($\mathrm{C}_{6} \mathrm{H}_{5}$ ) in TATB. Increasing the number of electron donating substituents groups of various strengths in the phenyl ring leads to lower $\mathrm{IP}_{a d}$ values. This is evident in the 
series of structures TNB (11.00) > TNT (10.54) > TNA (9.33) > TATB (8.56) eV. The addition of $\mathrm{H}_{2} \mathrm{C}-\mathrm{N}-\mathrm{NO}_{2}$ to $\mathrm{RDX}$ to transform it into $\mathrm{HMX}$, and containing both strong electron donating $\left(-\mathrm{NCH}_{2}\right)$ and withdrawing $\left(-\mathrm{NO}_{2}\right)$ groups, produces only a relatively lower $\mathrm{IP}_{a d}$ value, 10.09 and $9.73 \mathrm{eV}$, respectively.

Steric effects also play a role in producing different $\mathrm{IP}_{a d}$ and $\mathrm{EA}_{a d}$ values. Solid HMX exhibits three crystal polymorphs at ambient pressure, two of the important ones involved in its energy release process are $\beta$ and $\delta$ phases. [27, 28] Figure 2 shows the molecular conformations of these two phases: the chair $(\beta)$ and boat $(\delta)$ forms. The chair structure has a slightly higher $\mathrm{IP}_{a d}(9.73 \mathrm{eV})$ than the boat $(9.58 \mathrm{eV})$, indicating equal energy for the highest occupied molecular orbital (HOMO) in the two conformations. The chair form, however, produces almost double the value of $\mathrm{EA}_{a d}(1.86 \mathrm{eV})$ than the boat $(0.98 \mathrm{eV})$, which indicates a significant energy increase in lowest unoccupied molecular orbital (LUMO) for the $\delta$ structure. An interesting interfacial property related to organic photovoltaics might be noted here, if this trend were to also persist in the solid state, whereby an electron transfer process occurs from the LUMO of $\delta$-donor to that of the $\beta$-acceptor polymorph. [29] For comparison, a recent DFT study of $\delta$-HMX reported $\mathrm{IP}_{a d}$ of $10.10(9.24) \mathrm{eV}$ and $\mathrm{EA}_{a d}$ of 1.42 (1.67) eV using the functionals M06 (and PBE) and the 6-31+G(2df,p) basis set. [13] At the MP2/6-311++G(2d,p) level of theory, EA $\mathrm{A}_{a d}$ of $1.35 \mathrm{eV}$ for $\beta-\mathrm{HMX}$ was reported. [9] Both studies report significantly different $\mathrm{EA}_{a d}$ values than obtained here with the current G4 method.

It would be expected that molecules with the most electron withdrawing groups to have the largest $\mathrm{EA}_{a d}$ values, indicative of high stabilization of their anions. This is not universal, however, among the reported $\mathrm{EA}_{a d}$ values in Table I due to other factors such 
as steric effects and bond conjugations. CL-14 has one less $-\mathrm{NO}_{2}$ group, and thus shows a lower $\mathrm{EA}_{a d}$ value of $2.32 \mathrm{eV}$ than $\mathrm{CL}-17$, which has the largest $\mathrm{EA}_{a d}$ of all structures at $2.86 \mathrm{eV}$. Similarly, $\beta$-HMX has one more $-\mathrm{NO}_{2}$ group, yielding a larger $\mathrm{EA}_{a d}$ at $1.86 \mathrm{eV}$ than RDX at $1.04 \mathrm{eV}$, while steric effects reduce the value of $\delta$-HMX as noted above. TNA, TNB, TNT, and TATB all have three $-\mathrm{NO}_{2}$ groups, with somewhat similar $\mathrm{EA}_{a d}$ values at $2.33,2.17,2.02$, and $1.73 \mathrm{eV}$, respectively, the difference being for inclusion of various electron donating groups. The most pronounced exception is exhibited in PETN, which interestingly yields both the largest $\mathrm{IP}_{a d}(11.73 \mathrm{eV})$ and the lowest $\mathrm{EA}_{a d}(0.74 \mathrm{eV})$ of all molecules, indicative of a lower propensity to undergo an electron ejection or acceptance process. Finally, it should be noted that using the room-temperature enthalpies values that are also reported in Table I instead of the total energies will only change the calculated $\mathrm{IP}_{a d}$ and $\mathrm{EA}_{a d}$ values negligibly, at the most by $0.04 \mathrm{eV}$ in the case of $\mathrm{EA}_{a d}$ of $\beta$-HMX.

Recently, the enthalpies of formation $\Delta H_{f}^{0}(0 \mathrm{~K})$ and $\Delta H_{f}^{0}(298 \mathrm{~K})$ at 0 and 298.15 $\mathrm{K}$, respectively, were determined for several energetic molecules, including some considered in this study (among others): PETN, RDX, $\beta$-HMX, TNT, DADNE, and TATB, using the G2, G3, G4, and ccCA-PS3 composite methods. [26] Following the same computational approach in that study, the computed enthalpies of neutral species $\delta$ HMX, CL-17, TNB, CL-14, and TNA reported in Table I are used to calculate the atomization energies, and are combined with JANAF values for the atomic $\Delta H_{f}^{0}$ and for the standard state of the elements, $\left[H^{0}(298 \mathrm{~K})-H^{0}(0 \mathrm{~K})\right]_{S T},[30,31]$ to determine $\Delta H_{f}^{0}(0 \mathrm{~K})$ and $\Delta H_{f}^{0}(298 \mathrm{~K})$ of these species, and are reported in Table II. Of note, the reported $\Delta H_{f}^{0}(298 K)=55.5 \mathrm{kcal} / \mathrm{mol}$ of $\delta$-HMX is only slightly higher than 
$\Delta H_{f}^{0}(298 \mathrm{~K})=52.3 \mathrm{kcal} / \mathrm{mol}$ for $\beta$-HMX. [26] It should be noted that while $\Delta H_{f}^{0} \mathrm{G} 4$ computed values are consistently similar to those obtained from the G3 method, [32] they differ by as much as $\sim 8 \mathrm{kcal} / \mathrm{mol}$ for PETN from those obtained with the variant correlation consistent composite approach (ccCA-PS3). [24]

The calculated ionization potentials and electron affinities provide an opportunity for quantitative assessment of serval important physical properties that are usually invoked in determining the propensity of a material to undergo chemical or physical changes, thus related to its reactivity and stability. Chemical hardness, [33] is defined as $\eta=(\mathrm{IP}-\mathrm{EA}) / 2$, and is a measure of the molecular HOMO-LUMO energy gap. The principle of maximum hardness postulates as a rule of "nature" for molecules to arrange themselves to be as hard as possible. [34] Electronegativity, a classical structural chemistry concept defined as $\chi=(\mathrm{IP}+\mathrm{EA}) / 2$, is directly related to the chemical potential, $\mu=-\chi$. [35] Both of these two quantities continue to be used extensively to make predictions about chemical behavior, as in the Q-e scheme. [36, 37] Furthermore, physical hardness is a measure of the resistance to change of the nuclear positions in a system, [38] and is related to the bulk modulus or compressibility of the material. [14] An "intrinsic" physical hardness of a molecule, with a molecular volume $\mathrm{V}_{0}$, can be defined as $\eta^{*}=\eta / \mathrm{V}_{0}$, having the unit of pressure. For crystalline solids, it was shown that $V_{0} / \kappa$, where $\kappa$ is the compressibility, correlates with experimentally measured crystal hardness. [39]

Since X-ray and neutron diffraction data are available for all of the energetic molecules considered in this work (with the exception of CL-17) as shown in Table III, the molecular volume can also be determined. From the reported IP and EA values in 
Table I, the chemical hardness $\eta$, the electronegativity $\chi$, and the intrinsic physical hardness $\eta^{*}$ are determined and listed in Table III. Based on these values, the energetic molecules can be ordered in terms of decreasing $\eta$ as PETN $>$ RDX $>$ TNB $>$ TNT $=\delta$ HMX $>$ DADNE $>\beta$-HMX $>$ TNA $>$ TATB $>$ CL-17 $>$ CL-14, in terms of decreasing $\chi$ as $\mathrm{TNB}>\mathrm{TNT}>\mathrm{PETN}>\mathrm{CL}-17>\beta-\mathrm{HMX}=\mathrm{TNA}>\mathrm{RDX}>\mathrm{C}-14>\delta$-HMX $>\mathrm{TATB}>$ DADNE, and in terms of decreasing $\eta^{*}$ as DADNE $>$ RDX $>$ TNB $>$ TNT $=$ PETN $>$ TNA $>\delta$-HMX $>$ TATB $>\beta$-HMX $>$ CL- 14.

Finally, many attempts have been made to establish a correlation between a certain molecular property and the sensitivity of energetic materials to either shock or impact. [40] These included, among many others, molecular electronegativities and HUMO-LUMO gap. [15, 41] The lack of experimental data for shock sensitivity for pure materials, and the lack of uniformity of conditions in impact tests make correlation studies problematic and non-universal to include all energetic materials. It may well be that such correlation only exists within a structurally related group of molecules. In this vein, we note that the reported $\eta, \chi$, and $\eta *$ values in Table III for the homologous series TNB, TNT, TNA, and TATB show a uniform decrease in all of the three properties. The order of decreasing sensitivity based on available impact drop hammer tests for this series is $\operatorname{TNB}(71)>\mathrm{TNT}(98)>\mathrm{TNA}(121)>\mathrm{TATB}(345)$. [15, 40] 


\section{Acknowledgments:}

This work is performed under the auspices of the U.S. Department of Energy

Lawrence Livermore National Laboratory under Contract DE-AC52-07NA27344.

Funding support from the NSR\&D Special funds program is greatly appreciated. 


\section{Figure Captions:}

Figure 1. The 10 energetic molecules along with commonly used acronyms considered in the current study.

Figure 2. Molecular structures of the (a) $\beta$ (chair), and the (b) $\delta$ (boat) conformations of HMX. 
Table I. Total energies, enthalpies at $\mathrm{T}=298.15 \mathrm{~K}$, and zero-point vibrational energies of neutrals, cations, anions, and the corresponding $\mathrm{IP}_{a d}$ and $\mathrm{EA}_{a d .}{ }^{\mathrm{a}}$

\begin{tabular}{|c|c|c|c|c|c|c|c|c|}
\hline Molecule & Neutral & $\mathrm{ZPE}$ & Cation & $\mathrm{ZPE}$ & Anion & $\mathrm{ZPE}$ & $\mathrm{IP}_{a d}$ & $\mathrm{EA}_{a d}$ \\
\hline PETN & $\begin{array}{l}-1316.029668 \\
-1316.007883\end{array}$ & 116.9 & $\begin{array}{l}-1315.598643 \\
-1315.576353\end{array}$ & 113.2 & $\begin{array}{l}-1316.056912 \\
-1316.034064\end{array}$ & 112.8 & 11.73 & 0.74 \\
\hline RDX & $\begin{array}{l}-897.090086 \\
-897.076480\end{array}$ & 88.3 & $\begin{array}{l}-896.719150 \\
-896.705288\end{array}$ & 85.4 & $\begin{array}{l}-897.128410 \\
-897.114203\end{array}$ & 85.1 & 10.09 & 1.04 \\
\hline$\beta$-HMX & $\begin{array}{l}-1196.123877 \\
-1196.105446\end{array}$ & 118.5 & $\begin{array}{l}-1195.766410 \\
-1195.747271\end{array}$ & 115.9 & $\begin{array}{l}-1196.192291 \\
-1196.172422\end{array}$ & 114.8 & 9.73 & 1.86 \\
\hline$\delta$-HMX & $\begin{array}{l}-1196.118704 \\
-1196.100225\end{array}$ & 118.1 & $\begin{array}{l}-1195.766662 \\
-1195.747832\end{array}$ & 115.7 & $\begin{array}{l}-1196.154822 \\
-1196.135120\end{array}$ & 113.9 & 9.58 & 0.98 \\
\hline CL-17 & $\begin{array}{l}-1159.300858 \\
-1159.284074\end{array}$ & 74.5 & $\begin{array}{l}-1158.962982 \\
-1158.945645\end{array}$ & 73.4 & $\begin{array}{l}-1159.405835 \\
-1159.388604\end{array}$ & 72.7 & 9.19 & 2.86 \\
\hline TNB & $\begin{array}{l}-845.452747 \\
-845.439756\end{array}$ & 66.6 & $\begin{array}{l}-845.048403 \\
-845.034806\end{array}$ & 64.3 & $\begin{array}{l}-845.532528 \\
-845.519272\end{array}$ & 64.0 & 11.00 & 2.17 \\
\hline TNT & $\begin{array}{l}-884.729931 \\
-884.715348\end{array}$ & 83.7 & $\begin{array}{l}-884.342577 \\
-884.327125\end{array}$ & 81.3 & $\begin{array}{l}-884.804287 \\
-884.789419\end{array}$ & 81.4 & 10.54 & 2.02 \\
\hline CL-14 & $\begin{array}{l}-1010.216397 \\
-1010.201490\end{array}$ & 84.1 & $\begin{array}{l}-1009.906614 \\
-1009.891273\end{array}$ & 83.5 & $\begin{array}{l}-1010.301832 \\
-1010.286734\end{array}$ & 81.4 & 8.43 & 2.32 \\
\hline DADNE & $\begin{array}{l}-598.105038 \\
-598.094765\end{array}$ & 57.0 & $\begin{array}{l}-597.777253 \\
-597.766717\end{array}$ & 56.6 & $\begin{array}{l}-598.141867 \\
-598.131592\end{array}$ & 54.5 & 8.92 & 1.00 \\
\hline TNA & $\begin{array}{l}-900.793644 \\
-900.779725\end{array}$ & 77.5 & $\begin{array}{l}-900.450603 \\
-900.437271\end{array}$ & 76.1 & $\begin{array}{l}-900.879298 \\
-900.865287\end{array}$ & 75.5 & 9.33 & 2.33 \\
\hline TATB & $\begin{array}{l}-1011.469035 \\
-1011.453214\end{array}$ & 98.3 & $\begin{array}{l}-1011.154618 \\
-1011.138287\end{array}$ & 97.7 & $\begin{array}{l}-1011.532596 \\
-1011.516369\end{array}$ & 95.6 & 8.56 & 1.73 \\
\hline
\end{tabular}

${ }^{\mathrm{a}}$ Enthalpies values are below the total energies $E_{0}$, where $E_{0}=E_{e}+\mathrm{ZPE}$, both are in unit of Hartree. ZPE values are in $\mathrm{kcal} / \mathrm{mol}$. $\mathrm{IP}_{a d}$ and $\mathrm{EA}_{a d}$ are $\mathrm{eV}$. 
Table II. Enthalpies of formation $\Delta H_{f}^{0}(0 K)$ and $\Delta H_{f}^{0}(298 K)$ at 0 and $298.15 K .{ }^{a}$

\begin{tabular}{c|c|c}
\hline \hline Molecule & $\Delta \mathrm{H}_{\mathrm{f}}^{0}(0 \mathrm{~K})$ & $\Delta \mathrm{H}_{\mathrm{f}}^{0}(298 \mathrm{~K})$ \\
\hline -HMX & 69.6 & 55.5 \\
CL-17 & 82.1 & 74.5 \\
TNB & 15.4 & 9.7 \\
CL-14 & 65.0 & 56.3 \\
TNA & 12.8 & 5.6 \\
\hline
\end{tabular}

${ }^{\mathrm{a}}$ Units are in $\mathrm{kcal} / \mathrm{mol}$. 
Table III. Experimental crystal cells and molecular volumes, chemical hardness, electronegativity, and intrinsic molecular physical hardness. ${ }^{a}$

\begin{tabular}{c|c|r|r|r|r}
\hline \hline Compound & Cell Volume & $\mathrm{V}_{0}$ & $\eta$ & $\chi$ & $\eta^{*}$ \\
\hline PETN & $589.50^{\mathrm{b}}$ & 294.75 & 5.5 & 6.2 & 2.99 \\
RDX & $1633.86^{\mathrm{c}}$ & 204.23 & 4.5 & 5.6 & 3.57 \\
$\beta$-HMX & $517.16^{\mathrm{d}}$ & 259.70 & 3.9 & 5.8 & 2.44 \\
$\delta$-HMX & $1676.27^{\mathrm{d} 1}$ & 279.38 & 4.3 & 5.3 & 2.47 \\
CL-17 & $\mathrm{NA}^{\mathrm{N}}$ & $\mathrm{NA}$ & 3.2 & 6.0 & \\
TNB & $3377.73^{\mathrm{e}}$ & 211.10 & 4.4 & 6.6 & 3.34 \\
TNT & $1823.60^{\mathrm{f}}$ & 227.95 & 4.3 & 6.3 & 2.99 \\
CL-14 & $432.00^{\mathrm{g}}$ & 216.00 & 3.1 & 5.4 & 2.26 \\
DADNE & $515.90^{\mathrm{h}}$ & 128.98 & 4.0 & 5.0 & 4.91 \\
TNA & $854.43^{\mathrm{i}}$ & 213.61 & 3.5 & 5.8 & 2.63 \\
TATB & $442.49^{\mathrm{j}}$ & 221.24 & 3.4 & 5.1 & 2.46 \\
\hline
\end{tabular}

${ }^{\text {a }}$ Cell and molecular volumes are in $\AA^{3} . \eta$ and $\chi$ in eV. $\eta^{*}$ in GPa.

${ }^{\mathrm{b}}$ Ref. [42], ${ }^{\mathrm{c}}$ Ref. [43], ${ }^{\mathrm{d}}$ Ref. [44], ${ }^{\mathrm{d} 1}$ Ref. [28], ${ }^{\mathrm{e}}$ Ref. [45], ${ }^{\mathrm{f}}$ Ref. [46], ${ }^{\mathrm{g}}$ Ref. [47], ${ }^{\mathrm{h}}$ Ref. [48], ${ }^{\mathrm{i}}$ Ref. [49], ${ }^{\mathrm{j}}$ Ref. [50] 


\section{References:}

[1] S.C. Connors, The effects of gamma radiation on a PBX containing TATB and the fluoropolymer FK-800. Ph.D. Thesis, Canfield Uuniversity, 2014.

[2] M.H. Miles, K.L. DeVries, A.D. Britt, W.B. Moniz, Propell. Explos. Pyrotech. 8 (1983) 49.

[3] A.D. Britt, W.B. Moniz, G.C. Chingas, D.W. Moore, C.A. Heller, C.L. Ko, Propell. Explos., Pyrotech. 6 (1981) 94.

[4] M.R. Manaa, R.D. Schmidt, G.E. Overturf, B.E. Watkins, L.E. Fried, J.R. Kolb, Thermochim. Acta 384 (2002) 85.

[5] C.B. Skidmore, D.J. Idar, G.A. Buntain, S.F. Son, R.K. Sander, Aging and PBX 9502, Life Cycles of Energetic Materials, Fullerton, California, (1998) 143.

[6] D.S. Moore, Rev. Scient. Inst. 75 (2004) 2499.

[7] C. Mullen, A. Irwin, B.V. Pond, D.L. Huestis, M.J. Coggiola, H. Oser, Anal. Chem. 78 (2006) 3807.

[8] S. Boumsellek, S.H. Alajajian, A. Chutjian, J. Am. Soc. Mass Spectrom. 3 (1992) 243.

[9] J. Postler, M.M. Goulart, C. Matias, A. Mauracher, F.F. da Silva, P. Scheier, P. Limao-Vieira, S. Denifl, J. Am. Soc. Mass Spectrom. 24 (2013) 744.

[10] P. Sulzer, F. Rondino, S. Ptasinska, E. Illenberger, T.D. Mark, P. Scheier, Int. J. Mass Spectrom. 272 (2008) 149.

[11] A.V. Kimmel, P.V. Sushko, A.L. Shluger, M.M. Kuklja, J. Chem. Phys. 126 (2007) 10.

[12] M.M. Kuklja, Quantum-Chemical Modeling of Energetic Materials: Chemical Reactions Triggered by Defects, Deformations, and Electronic Excitations, in: J.R. Sabin (Ed.), Advances in Quantum Chemistry, Vol 69, Elsevier Academic Press Inc, San Diego, 2014, pp. 71-145.

[13] M.M. Kuklja, R.V. Tsyshevsky, O. Sharia, J. Am. Chem. Soc. 136 (2014) 13289.

[14] J.J. Gilman, Mater. Res. Innov. 1 (1997) 71.

[15] J. Sharma, B.C. Beard, M. Chaykovsky, J. Phys. Chem. 95 (1991) 1209.

[16] R.N. Compton, H.S. Carman, C. Desfrancois, H. AbdoulCarmine, J.P. Schermann, J.H. Hendricks, S.A. Lyapustina, K.H. Bowen, J. Chem. Phys. 105 (1996) 3472.

[17] X.S. Zhao, E.J. Hintsa, Y.T. Lee, J. Chem. Phys. 88 (1988) 801.

[18] J.C. Rienstra-Kiracofe, G.S. Tschumper, H.F. Schaefer, S. Nandi, G.B. Ellison, Chem. Rev. 102 (2002) 231.

[19] M. Musial, R.J. Bartlett, Chem. Phys. Lett. 384 (2004) 210.

[20] R.M. Richard, M.S. Marshall, O. Dolgounitcheva, J.V. Ortiz, J.L. Bredas, N. Marom, C.D. Sherrill, J. Chem. Theory and Comput. 12 (2016) 595.

[21] L.A. Curtiss, K. Raghavachari, P.C. Redfern, J.A. Pople, J. Chem. Phys. 112 (2000) 7374.

[22] L.A. Curtiss, P.C. Redfern, K. Raghavachari, J. Chem. Phys. 126 (2007) 084108.

[23] N.J. DeYonker, T.R. Cundari, A.K. Wilson, J. Chem. Phys. 124 (2006) 114104.

[24] N.J. DeYonker, B.R. Wilson, A.W. Pierpont, T.R. Cundari, A.K. Wilson, Molec. Phys. 107 (2009) 1107. 
[25] M.J. Frisch, G.W. Trucks, H.B. Schlegel, G.E. Scuseria, M.A. Robb, J.R.

Cheeseman, G. Scalmani, V. Barone, B. Mennucci, G.A. Petersson, H. Nakatsuji, M. Caricato, X. Li, H.P. Hratchian, A.F. Izmaylov, J. Bloino, G. Zheng, J.L.

Sonnenberg, M. Hada, M. Ehara, K. Toyota, R. Fukuda, J. Hasegawa, M. Ishida, T. Nakajima, Y. Honda, O. Kitao, H. Nakai, T. Vreven, J. Montgomery, J.A., J.E. Peralta, F. Ogliaro, M. Bearpark, J.J. Heyd, E. Brothers, K.N. Kudin, V.N.

Staroverov, T. Keith, R. Kobayashi, J. Normand, K. Raghavachari, A. Rendell, J.C. Burant, S.S. Iyengar, J. Tomasi, M. Cossi, N. Rega, J.M. Millam, M. Klene, J.E. Knox, J.B. Cross, V. Bakken, C. Adamo, J. Jaramillo, R. Gomperts, R.E. Stratmann, O. Yazyev, A.J. Austin, R. Cammi, C. Pomelli, J.W. Ochterski, R.L. Martin, K. Morokuma, V.G. Zakrzewski, G.A. Voth, P. Salvador, J.J.

Dannenberg, S. Dapprich, A.D. Daniels, O. Farkas, J.B. Foresman, J.V. Ortiz, J. Cioslowski, D.J. Fox, Gaussian 09, Revision B.01, Gaussian, Inc., Wallingford, CT, 2010.

[26] M.R. Manaa, L.E. Fried, I.F.W. Kuo, Chem. Phys. Lett. 648 (2016) 31.

[27] C.S. Choi, H.P. Boutin, Acta Cryst. B26 (1970) 1235.

[28] R.E. Cobbledick, R.W.H. Small, Acta Cryst. B30 (1974) 1918.

[29] J.L. Delgado, P.A. Bouit, S. Filippone, M.A. Herranz, N. Martin, Chem. Commun. 46 (2010) 4853.

[30] M.W. Chase, C.A. Davies, J.R. Downey, D.J. Frurip, R.A. McDonald, A.N. Syverud, J. Phys. Chem. Ref. Data 14 (1985) 1-926.

[31] L.A. Curtiss, K. Raghavachari, P.C. Redfern, J.A. Pople, J. Chem. Phys. 106 (1997) 1063.

[32] L.A. Curtiss, K. Raghavachari, P.C. Redfern, V. Rassolov, J.A. Pople, J. Chem. Phys. 109 (1998) 7764.

[33] R.G. Parr, R.G. Pearson, J. Am. Chem. Soc. 105 (1983) 7512.

[34] R.G. Pearson, J. Chem. Educ. 64 (1987) 561.

[35] W. Kohn, A.D. Becke, R.G. Parr, J. Phys. Chem. 100 (1996) 12974.

[36] C.G. Zhan, D.A. Dixon, J. Phys. Chem. A 106 (2002) 10311.

[37] C.G. Zhan, J.A. Nichols, D.A. Dixon, J. Phys. Chem. A 107 (2003) 4184.

[38] R.G. Pearson, J. Phys. Chem. 98 (1994) 1989.

[39] W. Yang, R.G. Parr, L. Uytterhoeven, Phys. Chem. Miner. 15 (1987) 191.

[40] B.M. Rice, J.J. Hare, J. Phys. Chem. A 106 (2002) 1770 (and references therein).

[41] J. Mullay, Propellants, Explos., Pyrotech. 12 (1987) 121.

[42] A.D. Booth, F.J. Llewellyn, J. Chem. Soc. (1947) 837.

[43] C.S. Choi, E. Prince, Acta Cryst. B28 (1972) 2857.

[44] Y. Kohno, K. Maekawa, N. Azuma, T. Tsuchioka, T. Hashizume, A. Imamura, Kogyo Kayaku 53 (1992) 227 (in Japenese).

[45] C.S. Choi, J.E. Abel, Acta Cryst. B28 (1972) 193.

[46] R.W. Carper, L.P. Davis, J. Phys. Chem. 86 (1982) 459.

[47] C.K. Low-Ma, W.P. Norris, The Crystal Structure of CL-14, A New, Dense, High Explosive, Naval Weapon Center, China Lake, CA, 1986.

[48] U. Bemm, H. Östmark, Acta Cryst. C54 (1998) 1997.

[49] J.R. Holden, C. Dickinson, J. Phys. Chem. 76 (1972) 3597.

[50] H.H. Cady, A.C. Larson, Acta Cryst. 18 (1965) 485. 
<smiles>O=[N+]([O-])OCC(CO[N+](=O)[O-])(CO[N+](=O)[O-])CO[N+](=O)[O-]</smiles>

[3-Nitrooxy-2,2-bis (nitrooxymethyl)propyl] nitrate PETN<smiles>Nc1c([N+](=O)[O-])c([N+](=O)[O-])c([N+](=O)[O-])c2nonc12</smiles>

7-amino-4,5,6-trinitrobenzofuroxan CL-17<smiles>Nc1c([N+](=O)[O-])c(N)c2nonc2c1[N+](=O)[O-]</smiles>

5,7-diamino-4,6-dinitrobenzofuroxan CL-14<smiles>Nc1c([N+](=O)[O-])c(N)c([N+](=O)[O-])c(N)c1[N+](=O)[O-]</smiles>

1,3,5-triamino-2,4,6-trinitrobenzene TATB<smiles>O=[N+]([O-])N1CN([N+](=O)[O-])CN([N+](=O)[O-])CN([N+](=O)[O-])C1</smiles>

Octaahydro-1,3,5,7-tetranitro1,3,5,7-tetraazacyclooctane HMX<smiles>Cc1c([N+](=O)[O-])cc([N+](=O)[O-])cc1[N+](=O)[O-]</smiles>

2,4,6--trinitrotoluene 2,4,6-TNT<smiles>O=[N+]([O-])N1CN([N+](=O)[O-])CN([N+](=O)[O-])C1</smiles>

Hexahydro-1,3,5-trinitro-

1,3,5-s-triazine RDX<smiles>O=[N+]([O-])c1cc([N+](=O)[O-])cc([N+](=O)[O-])c1</smiles>

1,3,5-trinitrobenzene TNB 1,1-diamino-2,2-dinitro-ethylene DADNE

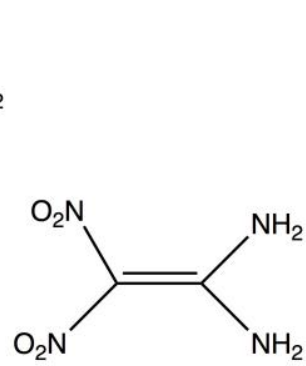<smiles>Nc1c([N+](=O)[O-])cc([N+](=O)[O-])cc1[N+](=O)[O-]</smiles>

2,4,6-trinitroaniline TNA 


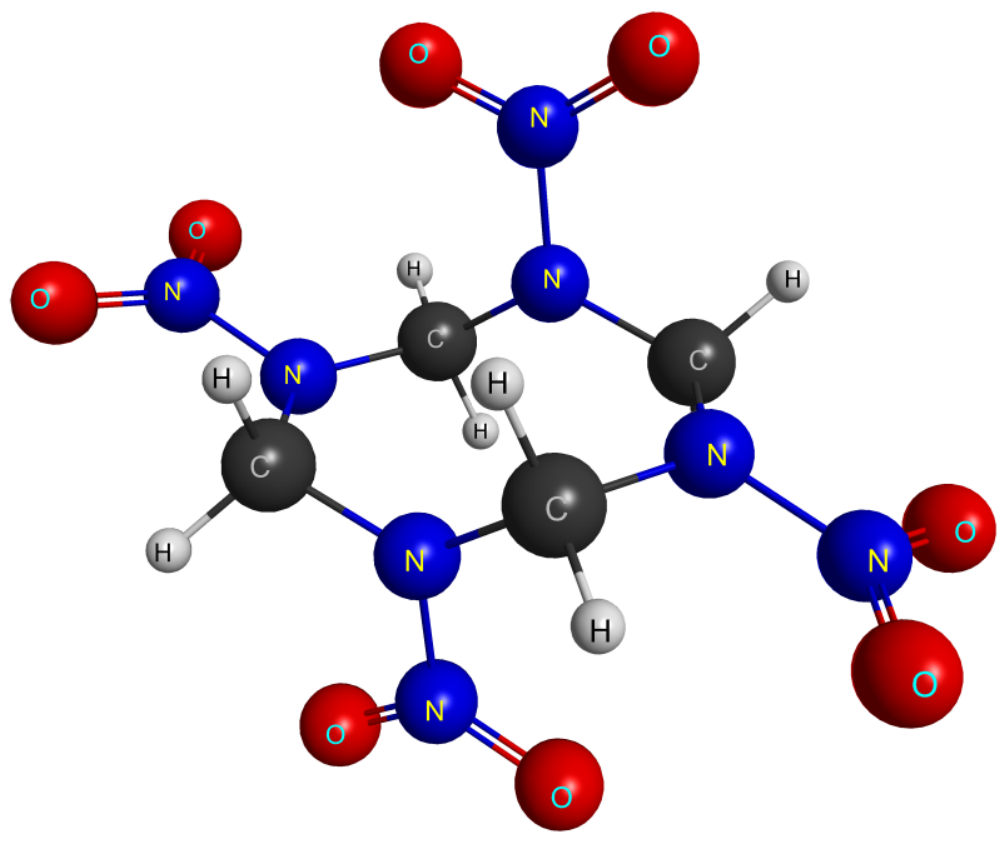




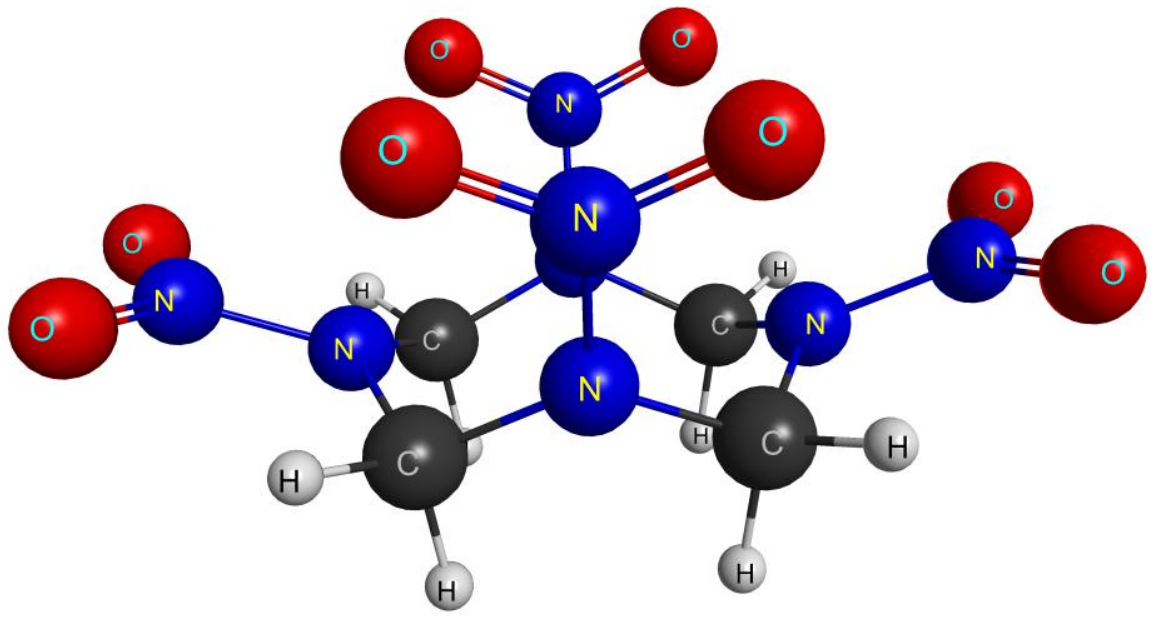



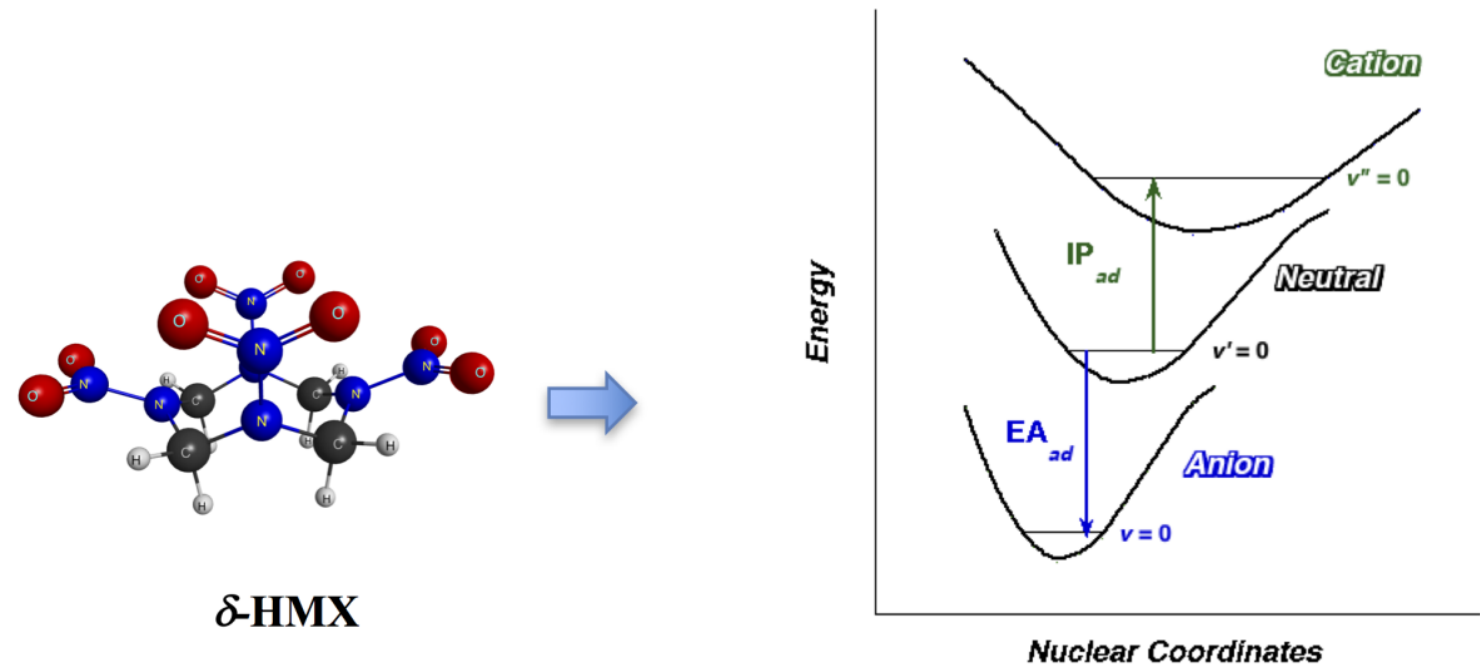